\title{
Unknown Primary Tumor cN3a TNM
}

\section{Finding v8}

National Cancer Institute

\section{Source}

National Cancer Institute. Unknown Primary Tumor CN3a TNM Finding v8. NCI

Thesaurus. Code C132663.

Unknown primary tumor with metastasis in a cervical lymph node larger than $6 \mathrm{~cm}$ in greatest dimension and ENE(-). (from AJCC 8th Ed.) 